\title{
The influence of chemotherapy-associated sinusoidal dilatation on short-term outcome after partial hepatectomy for colorectal liver metastases: A systematic review with meta-analysis
}

Citation for published version (APA):

van Mierlo, K. M. C., Zhao, J., Kleijnen, J., Rensen, S. S., Schaap, F. G., Dejong, C. H. C., \& Damink, S. W. M. O. (2016). The influence of chemotherapy-associated sinusoidal dilatation on short-term outcome after partial hepatectomy for colorectal liver metastases: A systematic review with meta-analysis. Surgical Oncology, 25(3), 298-307. https://doi.org/10.1016/j.suronc.2016.05.030

Document status and date:

Published: 01/09/2016

DOI:

10.1016/j.suronc.2016.05.030

Document Version:

Publisher's PDF, also known as Version of record

\section{Document license:}

Taverne

\section{Please check the document version of this publication:}

- A submitted manuscript is the version of the article upon submission and before peer-review. There can be important differences between the submitted version and the official published version of record. People interested in the research are advised to contact the author for the final version of the publication, or visit the $\mathrm{DOI}$ to the publisher's website.

- The final author version and the galley proof are versions of the publication after peer review.

- The final published version features the final layout of the paper including the volume, issue and page numbers.

Link to publication

\footnotetext{
General rights rights.

- You may freely distribute the URL identifying the publication in the public portal. please follow below link for the End User Agreement:

www.umlib.nl/taverne-license

Take down policy

If you believe that this document breaches copyright please contact us at:

repository@maastrichtuniversity.nl

providing details and we will investigate your claim.
}

Copyright and moral rights for the publications made accessible in the public portal are retained by the authors and/or other copyright owners and it is a condition of accessing publications that users recognise and abide by the legal requirements associated with these

- Users may download and print one copy of any publication from the public portal for the purpose of private study or research.

- You may not further distribute the material or use it for any profit-making activity or commercial gain

If the publication is distributed under the terms of Article $25 \mathrm{fa}$ of the Dutch Copyright Act, indicated by the "Taverne" license above,

Download date: 26 Apr. 2023 


\title{
The influence of chemotherapy-associated sinusoidal dilatation on short-term outcome after partial hepatectomy for colorectal liver metastases: A systematic review with meta-analysis
}

\author{
Kim M.C. van Mierlo a, ${ }^{\text {, Junfang Zhao }}{ }^{\text {a, }}$, Jos Kleijnen ${ }^{\text {b, c }}$, Sander S. Rensen ${ }^{\text {, }}$, \\ Frank G. Schaap a , Cornelis H.C. Dejong a, d, Steven W.M. Olde Damink ${ }^{\text {a, e, * }}$ \\ ${ }^{a}$ Department of Surgery, Maastricht University Medical Centre \& NUTRIM School of Nutrition and Translational Research in Metabolism, Maastricht \\ University, Universiteitssingel 40, 6229 ER, Maastricht, The Netherlands \\ ${ }^{\mathrm{b}}$ Kleijnen Systematic Reviews Ltd, York, United Kingdom \\ ${ }^{\mathrm{c}}$ CAPHRI School for Public Health and Primary Care, Maastricht University, Universiteitssingel 40, 6229 ER, Maastricht, The Netherlands \\ d GROW School for Oncology and Developmental Biology, Maastricht University, Universiteitssingel 40, 6229 ER, Maastricht, The Netherlands \\ e Department of HPB Surgery \& Liver Transplantation, Institute for Liver and Digestive Health, Royal Free Hospital, University College London, London, \\ United Kingdom
}

\section{A R T I C L E I N F O}

\section{Article history:}

Received 31 March 2016

Accepted 30 May 2016

\section{Keywords:}

Sinusoidal dilatation

Sinusoidal obstruction syndrome

SOS

Partial hepatectomy

Postoperative liver failure

Chemotherapy-associated liver injury

\begin{abstract}
A B S T R A C T
Summary background data: Hepatic sinusoidal dilatation (SD) is a histopathological entity that occurs in up to $75 \%$ of patients undergoing oxaliplatin-based chemotherapy for colorectal liver metastases (CRLM). Objective: To study the influence of SD on outcome after partial hepatectomy in patients with CRLM. Methods: Medline, Embase, CENTRAL, LILACS and CINAHL were searched for studies published between 01.01.2004 and 09.06.2015 with keywords: "sinusoidal obstruction syndrome", "hepatic veno-occlusive disease", and "Stuart-Bras syndrome". Studies comprising adults who underwent partial hepatectomy for CRLM with grading of SD and registration of postoperative morbidity and/or mortality were included. Risk of bias and quality of studies were evaluated with the Quality In Prognosis Studies Instrument (QUIPS) and modified GRADE framework.

Results: Search strategies produced 2007 hits from which 23 and 13 articles were extracted for qualitative and quantitative analyses, respectively. Meta-analysis on the influence of SD grade $2-3$ vs. SD grade $0-1$ on postoperative overall morbidity showed an odds ratio (OR) of 1.26 [95\% CI 0.74 , $2.15](\mathrm{p}=0.40)$, an OR of $1.03[0.15,6.89](\mathrm{p}=0.98)$ for liver failure, an OR of $1.21[0.23,6.35](\mathrm{p}=0.82)$ for overall mortality, and an OR of $3.52[0.31,39.91](\mathrm{p}=0.31)$ for liver-related morbidity. QUIPS showed a low to high risk of bias for studies, and GRADE showed very low quality of evidence per outcome. Conclusions: No significant effect of SD grade 2-3 on short-term outcome after partial hepatectomy was found. However, the data on which this conclusion was based were not very robust and therefore no solid conclusions could be drawn.
\end{abstract}

() 2016 Elsevier Ltd. All rights reserved.

\footnotetext{
* Corresponding author. Department of Surgery, Maastricht University Medical Centre \& NUTRIM School of Nutrition and Translational Research in Metabolism, Maastricht University, Universiteitssingel 40, 6229 ER, Maastricht, The Netherlands

E-mail addresses: k.vanmierlo@maastrichtuniversity.nl (K.M.C. van Mierlo), junfang.zhao@maastrichtuniversity.nl (J. Zhao), jos@systematic-reviews.com (J. Kleijnen), s.rensen@maastrichtuniversity.nl (S.S. Rensen), frank.schaap@ maastrichtuniversity.nl (F.G. Schaap), chc.dejong@mumc.nl (C.H.C. Dejong), steven.oldedamink@maastrichtuniversity.nl (S.W.M. Olde Damink).

${ }^{1}$ These authors contributed equally to this study.
}

\section{Introduction}

Sinusoidal dilatation (SD) is a common manifestation of hepatotoxicity that occurs in patients with colorectal liver metastases (CRLM) after administration of oxaliplatin-based chemotherapy [1-3]. Regimens based on the platinum containing agent oxaliplatin are used extensively as neo-adjuvant therapy to downsize initially irresectable CRLM, with convincing response rates and survival outcomes [4-6]. However, liver injury is demonstrated in over $75 \%$ of patients $[1,3]$.

$\mathrm{SD}$ is part of a broad range of liver injuries due to specific drugs, 
in conjunction with sinusoidal obstruction syndrome (SOS). SOS is macroscopically identified as 'blue liver' and microscopically characterized by injury of the sinusoidal endothelial cells (SECs), parenchymal lesions (e.g. SD and peliosis), venular lesions, and fibrosis. Various pathogenic factors have been described to contribute to these histopathological changes [7]. Key features of oxaliplatin-induced toxicity are its reaction with reduced glutathione and F-actin depolymerization, which results in rounding up and subsequent dehiscence of SECs and obstruction of sinusoidal blood flow leading to SD and erythrocyte extravasation [1,8-12]. Activation of hepatic stellate cells (HSC) results in neodisposition of collagen bundles in the perisinusoidal space which, in combination with subendothelial fibroblast activation in the terminal hepatic vein, leads to fibrotic venular occlusion. In the last stage of SOS, dense perivenular fibrosis is observed and hepatic vein lumina can no longer be identified [13].

The grading system of Rubbia-Brandt et al. classifies all histological features of SOS including SD, and is routinely used for stipulating severity [1,2]. In most studies, SD functions as the standard for liver damage. Reversibility of sinusoidal injury is discussed widely, and although human and animal models show ceasing of pathological features at repeated hepatic resection [2,14], other studies show persistence or progression of lesions even after cessation of chemotherapy [15].

Clinical importance of SD is reflected in the development of hepatomegaly, ascites, splenomegaly, thrombocytopenia, portal hypertension, and systemic elevation of liver enzymes [16-19]. With regard to liver surgery, a diminished preoperative functional reserve, (transient) postoperative liver failure, higher morbidity rates and longer hospital stay, as well as impairment of postoperative liver regeneration have been reported [20,21]. Numerous studies have shown a negative influence of SD on postoperative outcome [20,22,23], yet others could not reproduce this [24-29]. This systematic review with meta-analysis aimed to determine the influence of SD on short-term outcome after partial hepatectomy in patients with CRLM.

\section{Methods}

\subsection{Criteria for considering studies for this review}

An extensive study protocol can be found in Appendix 1 (Supplementary data). This review was conducted and reported in compliance with the PRISMA and MOOSE guidelines, and followed the Cochrane protocol for prognostic factor reviews [30-32]. Studies were considered eligible for inclusion in this review when they met the following criteria: (I) studies comprising adults $(\geq 18$ years old) with CRLM, (II) who underwent minor or major partial hepatectomy, (III) with postoperative histological grading of SD in liver tissue distant from the tumour according to the scoring system of Rubbia-Brandt, (IV) and with registration of overall morbidity, liver-related morbidity, liver failure, or overall mortality ( $\leq 90$ days or in-hospital) after liver resection. Case reports, comments/editorials, published abstracts, and reviews were rejected, in addition to records not covering the subject or including non-adults $(<18$ years old). Cohort studies including patients who underwent liver surgery for malignancies other than CRLM were included albeit that this group comprised less than $30 \%$ of the total study population. No distinction was made between first and repeated resections, and studies with patients who underwent preoperative portal vein embolization (PVE) were allowed for inclusion since an effect of PVE on outcome in patients with SD was observed in a single study only [33].

\subsection{Search methods for identification of studies}

Search strategies in international databases Medline, Embase, Cochrane Central Register of Controlled Trials (CENTRAL), Latin American and Caribbean Health Sciences Literature (LILACS) and Cumulative Index to Nursing and Allied Health Literature (CINAHL) were performed between 01.01.2004 and 09.06.2015 using the following keywords (adjusted to the relevant database and including synonyms): "sinusoidal obstruction syndrome", "hepatic veno-occlusive disease", and "Stuart-Bras syndrome". Publication date of the search strategy was set from January 2004 onwards because the widely used criterion for scoring SD from RubbiaBrandt et al. was developed in this year [1]. The Embase strategy was independently peer reviewed by a second information specialist using the Canadian Agency for Drugs and Technologies in Health (CADTH) checklist [34]. No language restrictions or other limitations were applied. Details of the search strategy can be found in Appendix 2.

\subsection{Data collection and analysis}

Records were downloaded in EndNote ${ }^{\circledR} \mathrm{X} 7$ and duplicates were automatically and manually removed. All abstracts were screened by two independent reviewers (KvM, JZ), and in the rare case of no consensus the abstract was considered for full-text scanning. One of the reviewers (KvM) screened citations of all full-text articles for additional records on the base of title or abstract. Previous research from the authors on this topic resulted in an extensive own library which was also checked for references. Records considered for fulltext assessment were screened independently by two reviewers (KvM, JZ). Full-text articles were screened for inclusion in qualitative analysis and/or quantitative analysis. Articles without postoperative mortality in the study population were described qualitatively due to lack of contribution to quantitative analysis.

\subsection{Data extraction and definitions}

Data extraction was performed independently by two reviewers (KvM, JZ) using a data extraction form in Excel specifically created for this study. Any dissimilarity in data was discussed and solved by consensus. Inter-observer agreement was calculated with Cohen's kappa coefficient. All information on study design and characteristics, main outcomes and possible overlap in cohort data was recorded. SD was defined according to the grading system of Rubbia-Brandt et al. [2]. In short; SD 0: absence of signs of SD; 1 : mild SD (centrilobular involvement limited to one-third of the lobular area); 2 : moderate SD (centrilobular involvement extending in two-thirds of the lobular area) and 3: severe SD (complete lobular involvement or centrilobular involvement extending to adjacent lobules with bridging congestion). In all analyses, 'SD' was defined as the presence of grade 2 or 3 SD whilst 'no SD' was defined as grade 0 or 1 . We considered SD grade $2-3$ clinically more relevant than grade $0-1$, since rupture of sinusoidal wall integrity is present in grade 2 and higher. Major liver resections were defined as resection of $\geq 3$ Couinaud segments. All outcomes were measured between 30 and 90 days after partial hepatectomy or during initial hospital admission ('in-hospital'). Primary outcomes were overall morbidity, liver failure, and overall mortality after liver resection. Secondary outcome was liver-related morbidity after partial hepatectomy. Overall morbidity was defined as any complication (i.e. surgical and medical, excluding death) after liver resection, irrespective of severity [35]. Mortality was defined as death due to any cause after liver resection. Since consensus on the definition of liver failure is lacking [36-38], definitions were specified in the Results Section. Liver-related morbidity was 
defined as any liver-related complication (e.g. bile leakage, liver abscess, liver failure) occurring after partial hepatectomy, regardless of severity [39].

\subsection{Quality assessment}

Risk of bias of individual studies was determined using the Quality In Prognosis Studies (QUIPS) Risk of Bias Assessment Instrument for Prognostic Factor Studies [40,41]. The QUIPS instrument is a checklist composed of the domains study participation, study attrition, prognostic factor measurement, outcome measurement, study confounding, and statistical analysis and reporting, and produces an estimation of the risk of bias with help of a rating (high, moderate or low risk) per domain. The following definitions were chosen by the authors for rating the overall risk of bias: 'overall low risk of bias' was $\leq 2$ domains rated as moderate risk and the remaining domains as low, 'overall moderate risk of bias' was $\geq 3$ domains rated as moderate risk and the remaining domains as low, 'overall high risk of bias' was $\geq 1$ domain rated as high risk, independent of the rating of the remaining domains. The quality of evidence per primary or secondary outcome was evaluated using the modified Grading of Recommendations Assessment, Development and Evaluation (GRADE) framework for prognosis studies [30,42], which is composed of eight scoring fields and aims to give an objective scoring of quality of evidence per outcome specific for the hypothesis of the user. Its fixed scoring parameters and rationale for downgrading described in the Summary of Findings Table makes GRADE the most transparent and reproducible method currently available. The starting score is based on the study design and quality can be downgraded (and in specific cases upgraded) per field. Quality of evidence is defined as (I) high quality: the true effect lies close to the estimate of the effect, (II) moderate quality: the true effect is likely to be close to the estimate of the effect, but there is a possibility that it is substantially different, (III) low quality: the true effect may be substantially different from the estimate of the effect or (IV) very low quality: the true effect is likely to be substantially different from the estimate of effect [30].

\subsection{Data handling and statistical methods}

Meta-analyses of two or more studies per outcome were performed in Review Manager 5.3 and depicted in forest plots. The principal effect measures consisted of a pooled odds ratio (OR) with 95\% confidence intervals $(95 \% \mathrm{CI}$ ) calculated by the MantelHaenszel test for dichotomous outcomes, which was chosen because of low event rates and small sample sizes. A p-value $<0.05$ was considered significant. A random effects model was chosen instead of fixed effects because the true effect size was expected to vary between different studies. Statistical heterogeneity was evaluated with the $\mathrm{X}^{2}$ test, $\mathrm{I}^{2}$, and comparison of point estimates between studies and overlap of $95 \%$ confidence intervals. Clinical heterogeneity was investigated by comparing different patient populations (SD 2-3 vs. SD 0-1; SD 1-3 vs. SD 0) and different extents of liver resection (all resections vs. major resections only). In case of significant heterogeneity, defined as an $\mathrm{I}^{2} \geq 65 \%$ and a $\mathrm{X}^{2}$ test p-value of $<0.10$ (considered significant due to a potentially low number of included studies in meta-analyses), the OR and 95\% CI were omitted from the forest plot.

\section{Results}

\subsection{Search results}

The conducted search resulted in a total of 2777 hits. Fig. 1 shows the selection process of included studies in detail. After duplicate removal, 2007 hits remained. A total of 50 full-text articles were assessed for eligibility. Four more records were selected for full-text article scanning during reference checking, and another four potentially relevant records were selected from the own library. After application of the predefined inclusion and exclusion criteria on the total of 58 full-text articles by the two reviewers (KvM, JZ), 23 articles were included in qualitative synthesis. Inter-observer agreement kappa was 0.81 and dissimilarity was solved by discussion. Of the included studies for qualitative analysis, 13 studies contained data for quantitative analysis. Study and patient characteristics, main outcomes and main conclusions of the studies are summarized in Table 1.

\subsection{Included studies}

A total of eight studies could be included in quantitative analysis to estimate the effect of SD grade $2-3 v s$. SD grade $0-1$ on postoperative outcomes after partial hepatectomy. All studies but two were retrospective cohort studies which enrolled at least 50 patients $[22,56]$. Each study was published in an international, peerreviewed journal between 2006 and 2013. Postoperative morbidity could be evaluated in two studies comprising a total of 248 patients [26,44], and in two studies encompassing a total of 319 patients, postoperative liver failure was studied [47,56]. Three studies investigated postoperative mortality in a total of 702 patients $[21,55,56]$, and postoperative liver-related morbidity was evaluated in two studies with a total of 147 patients [22,26]. For each of above outcomes, a single study addressed the effect of SD in patients undergoing major liver resection [26,53].

\subsection{Patient characteristics}

All cohort studies included patients who underwent minor or major hepatectomy and of whom liver quality was assessed postoperatively according to the grading system of Rubbia-Brandt [1]. In total $63 \%$ of patients who underwent surgery were male, and median age was 61 years [range: 18 to 89]. CRLM was the indication for liver surgery in all patients.

\subsection{Primary outcomes}

\subsubsection{Postoperative morbidity}

A meta-analysis on the influence of SD grade 2-3vs. SD grade $0-1$ on postoperative morbidity was conducted and depicted in Fig. 2A. The overall effect of SD vs. no SD on postoperative morbidity showed a p-value of 0.40 with an OR of 1.26 [95\% CI 0.74-2.15]. Tests evaluating consistency of results showed an $\mathrm{I}^{2}$ of $0 \%$ and a $\mathrm{X}^{2}$ test p-value of 0.74 . Although the use of random effects was deliberately chosen, testing with fixed effects did not have influence on the results (OR 1.26 [95\% CI 0.73-2.15], $\mathrm{p}=0.40$ ). SD was no risk factor for morbidity in studies where original data was not provided for quantitative analysis $[21,24,50,55]$.

In patients undergoing major hepatectomy $(n=59$, hemihepatectomy or extended hemihepatectomy), 17 out of 29 patients (59\%) with SD developed morbidity vs. 19 out of 30 patients (63\%) in patients without SD (not depicted in forest plot) [26].

\subsubsection{Postoperative liver failure}

The effect of SD on postoperative liver failure (PLF) could be tested in two studies (Fig. 2B). In the study of Kishi et al., liver failure was defined as peak total bilirubin value $>120 \mu \mathrm{mol} / \mathrm{L}$ in the postoperative course [47], while Vigano et al. applied serum bilirubin $>50 \mu \mathrm{mol} / \mathrm{L}$ and/or prothrombin time $<50 \%$ on or after postoperative day (POD) 5 [56]. An OR of 1.03 [95\% CI 0.15-6.89] 


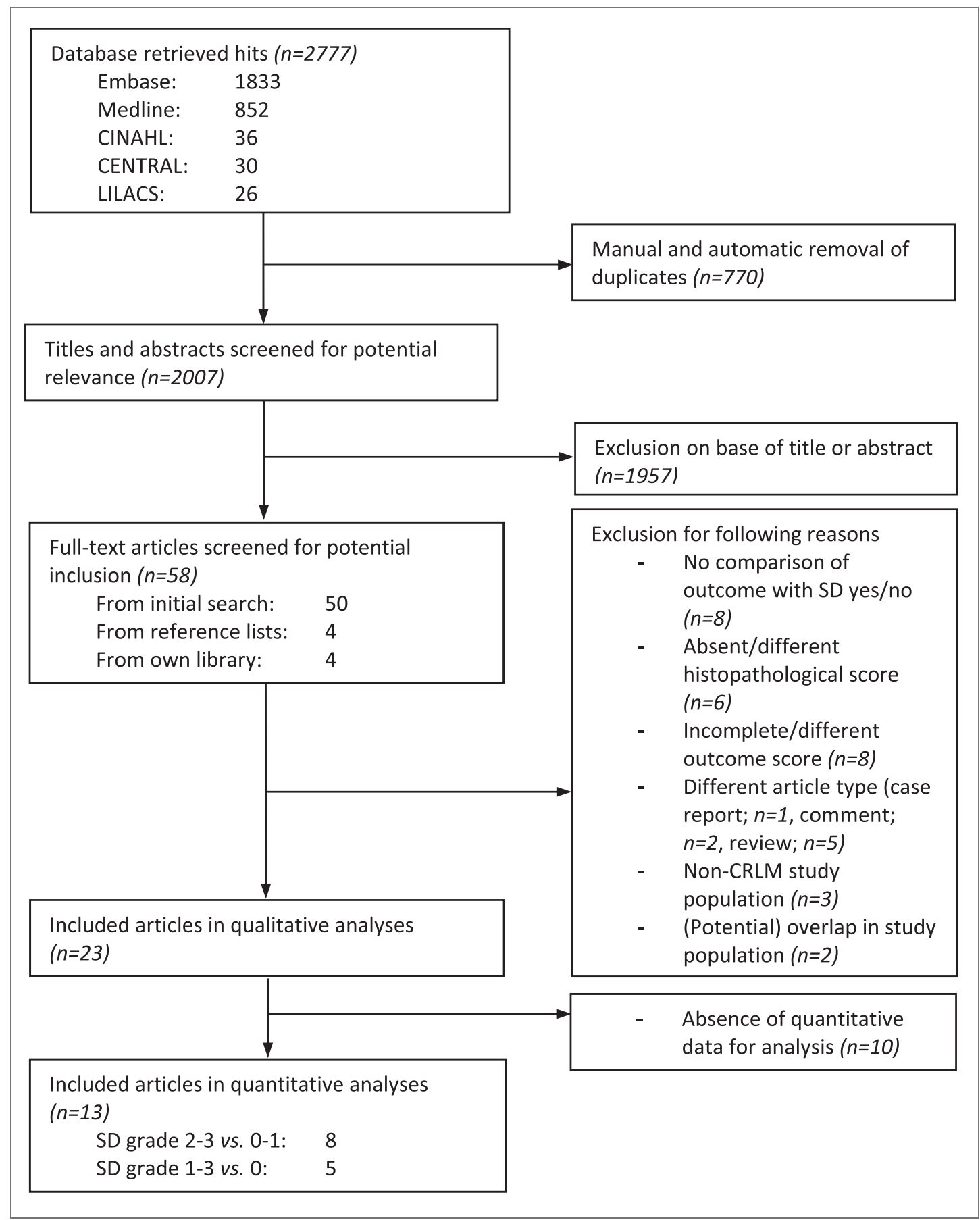

SD; sinusoidal dilatation, CINAHL; Cumulative Index to Nursing and Allied Health Literature, CENTRAL; Cochrane Central Register of Controlled Trials, LILACS; Latin American and Caribbean Health Sciences Literature, CRLM; colorectal liver metastases

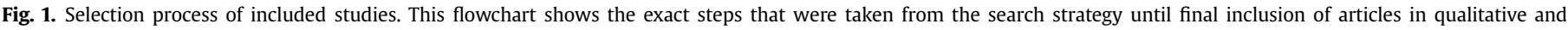

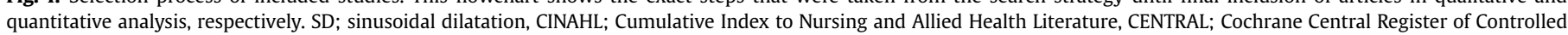
Trials, LILACS; Latin American and Caribbean Health Sciences Literature, CRLM; colorectal liver metastases.

was found with a p-value of 0.98 for SD. Significant heterogeneity between studies was reflected in an $\mathrm{I}^{2}$ of $65 \%$ and $\mathrm{p}$-value of $\mathrm{X}^{2}$ test of 0.09 , and overlap in $95 \% \mathrm{CI}$ was barely present. Totals were subsequently omitted from the forest plot. One qualitative study showed no PLF in both the patients with or without SD [23].

The study of Soubrane et al. was the only study that looked at postoperative liver failure in major resections only, and defined liver failure as a serum bilirubin $>50 \mu \mathrm{mol} / \mathrm{L}$ and prothrombin time $<50 \%$ on POD5 [53]. Liver failure occurred in eight of 38 patients with SD vs. zero in 13 patients without SD (not depicted in forest plot).

\subsubsection{Postoperative mortality}

Three studies were available for examining the influence of SD 
Table 1

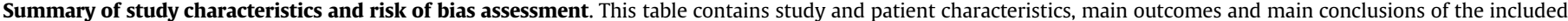
studies.

\begin{tabular}{|c|c|c|c|c|c|c|c|c|}
\hline Name & Year & Country & $\mathrm{n}$ & Comparison & $\begin{array}{l}\text { Study } \\
\text { design }\end{array}$ & $\begin{array}{l}\text { Quant/ } \\
\text { Qual }\end{array}$ & $\begin{array}{l}\text { QUIPS } \\
\text { score }\end{array}$ & Main outcome \\
\hline $\begin{array}{c}\text { Aloysius } \\
\text { [43] }\end{array}$ & 2007 & UK & 50 & $\begin{array}{l}3 \text { vs. } 2 \text { vs. } 1 \\
\text { vs. } 0\end{array}$ & RCohS & Qual & High & Folfox-4 therapy is associated with SD and hepatic steatosis \\
\hline $\begin{array}{l}\text { Brouquet } \\
\quad[44]\end{array}$ & 2009 & France & 146 & $2-3$ vs. $0-1$ & RCohS & Quan & High & $\begin{array}{l}\text { Morbidity rate is significantly increased in patients with CALI compared to patients without } \\
\text { CALI }\end{array}$ \\
\hline $\begin{array}{l}\text { Gomez- } \\
\quad \text { Ramirez } \\
{[22]}\end{array}$ & 2010 & Spain & 45 & $2-3$ vs. $0-1$ & PCohS & Quan & Low & $\begin{array}{l}\text { Patients treated with oxaliplatin have a higher incidence of SOS, increase in liver } \\
\text { complications and longer mean hospital stay }\end{array}$ \\
\hline Hubert [45] & 2010 & Belgium & 114 & 3 vs. $0-2$ & RCohS & Qual & Low & $\begin{array}{l}\text { Neoadjuvant Ctx is significantly associated with SD but does not affect postoperative clinical } \\
\text { outcome }\end{array}$ \\
\hline Imai [19] & 2014 & Japan & 55 & $2-3$ vs. $0-1$ & RCohS & Qual & High & $\begin{array}{l}\text { Ox-based Ctx is related to SD, and patients with SD have a significantly higher increase in } \\
\text { splenic volume }\end{array}$ \\
\hline $\begin{array}{l}\text { Kandutsch } \\
{[24]}\end{array}$ & 2008 & Austria & 63 & $\begin{array}{l}3 \text { vs. } 2 \text { vs. } 1 \\
\text { vs. } 0\end{array}$ & RCohS & Qual & High & Sinusoidal dilatation is not associated with postoperative morbidity \\
\hline Karoui [46] & 2006 & France & 67 & $1-3$ vs. 0 & RCohS & Qual & Low & $\begin{array}{l}\text { Prolonged neoadjuvant Ctx alters liver parenchyma and increases morbidity after major } \\
\text { resection under total hepatic vascular exclusion }\end{array}$ \\
\hline Kishi [47] & 2010 & Italy & 219 & $2-3$ vs. $0-1$ & RCohS & Quan & Low & SI is not a risk factor for the development of liver insufficiency \\
\hline Komori [25] & 2010 & Japan & 27 & $\begin{array}{l}3 \text { vs. } 2 \text { vs. } 1 \\
\text { vs. } 0\end{array}$ & RCohS & Qual & High & $\begin{array}{l}\text { Folfox- } 4 \text { therapy is associated with SD. Ctx does not increase postoperative morbidity and } \\
\text { mortality in patients }\end{array}$ \\
\hline $\begin{array}{l}\text { Makowiec } \\
{[26]}\end{array}$ & 2011 & Germany & 102 & $2-3$ vs. $0-1$ & RCohS & Quan & Low & Neither preoperative CTx nor liver injury increase perioperative morbidity \\
\hline Mentha [15] & 2009 & Switzerland & 23 & $\begin{array}{l}3 \text { vs. } 2 \text { vs. } 1 \\
\text { vs. } 0\end{array}$ & RCohS & Qual & High & $\begin{array}{l}\text { Neoadjuvant Ctx followed by two-step hepatectomy with right portal vein occlusion is } \\
\text { feasible and safe }\end{array}$ \\
\hline Miura [48] & 2011 & Japan & 14 & $2-3$ vs. $0-1$ & RCohS & Qual & High & $\begin{array}{l}\text { APRI and SVI help indicate the risk of CALI. The incidence of SD was significantly higher in the } \\
\text { SVI } \geq 30 \% \text { compared to the SVI }<30 \% \text { group }\end{array}$ \\
\hline Nakano [20] & 2008 & France & 90 & $1-3$ vs. 0 & RCohS & Quan & Mod & $\begin{array}{l}\text { SI is significantly associated with higher morbidity and longer hospital stay in patients } \\
\text { undergoing a major hepatectomy }\end{array}$ \\
\hline${ }^{a}$ Narita [33] & 2011 & France & $\begin{array}{l}42 / \\
45\end{array}$ & $1-3$ vs. 0 & RCohS & Quan & Low & $\begin{array}{l}\text { SOS has a negative impact on hypertrophy following PVE and is associated with a higher risk } \\
\text { of postoperative liver failure after major hepatectomy }\end{array}$ \\
\hline a Narita [49] & 2012 & France/USA & 101 & $1-3$ vs. 0 & RCohS & Quan & Low & $\begin{array}{l}\text { Ox-based Ctx is associated with a significantly increased occurrence of SD, but SD does not } \\
\text { impair early postoperative outcome }\end{array}$ \\
\hline $\begin{array}{l}\text { Nguyen- } \\
\text { Khac [50] }\end{array}$ & 2013 & France & 50 & $1-3$ vs. 0 & RCohS & Quan & Low & Ctx of CRLM induces SD related to oxaliplatin, without impact on postoperative mortality \\
\hline $\begin{array}{l}\text { bessaux } \\
\quad[51]\end{array}$ & 2010 & France & 52 & 1 vs. 2 & RCohS & Qual & High & $\begin{array}{l}\text { The addition of cetu to neoadjuvant Ctx does not increase postoperative morbidity or the } \\
\text { occurrence of SD }\end{array}$ \\
\hline $\begin{array}{l}\text { bessaux } \\
\text { [52] }\end{array}$ & 2010 & France & 72 & 1 vs. 2 & RCohS & Qual & High & $\begin{array}{l}\text { The addition of cetu or bev to neoadjuvant Ctx does not increase postoperative morbidity or } \\
\text { the occurrence of SD }\end{array}$ \\
\hline $\begin{array}{l}\text { Soubrane } \\
\text { [53] }\end{array}$ & 2010 & France & 78 & $2-3$ vs. $0-1$ & RCohS & Quan & Low & $\begin{array}{l}\text { High grade SI leads to an increased risk of postoperative complications following major } \\
\text { resection }\end{array}$ \\
\hline $\begin{array}{l}\text { Takamoto } \\
\text { [23] }\end{array}$ & 2010 & Japan & 51 & $\begin{array}{l}3 \text { vs. } 2 \text { vs. } 1 \\
\text { vs. } 0\end{array}$ & RCohS & Qual & Mod & The amount of blood loss during surgery is significantly higher in patients with liver injury \\
\hline $\begin{array}{l}\text { Tamandl } \\
{[21]}\end{array}$ & 2011 & Austria & 196 & $2-3$ vs. $0-1$ & RCohS & Quan & High & SD due to ox-based Ctx can lead to early recurrence and decreased survival \\
\hline $\begin{array}{l}\text { Van der Pool } \\
\text { [54] }\end{array}$ & 2012 & Netherlands & 104 & $1-3$ vs. 0 & RCohS & Quan & Low & $\begin{array}{l}\text { Neither duration of ox-based CTx nor time interval between cessation of ox-based CTx and } \\
\text { surgery are associated with postoperative complications }\end{array}$ \\
\hline $\begin{array}{l}\text { Vauthey } \\
\text { [55] }\end{array}$ & 2006 & USA/Italy & 406 & $2-3$ vs. $0-1$ & RCohS & Quan & Low & $\begin{array}{l}\text { Preoperative ox-based Ctx is associated with SI but not with increased morbidity or mortality } \\
\text { rates }\end{array}$ \\
\hline Vigano [56] & 2012 & Italy & 100 & $2-3$ vs. $0-1$ & PCohS & Quan & Low & The rate of liver dysfunction is high among patients with moderate to severe CALIs \\
\hline Wolf [57] & 2013 & USA & 384 & $1-3$ vs. 0 & RCohS & Quan & Low & No association is found between oxaliplatin use and SI or SI and postoperative morbidity \\
\hline
\end{tabular}

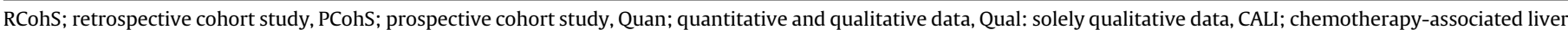

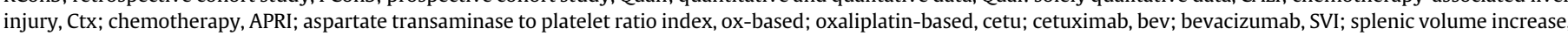
SOS; sinusoidal obstruction syndrome, SD; sinusoidal dilatation, SI; sinusoidal injury, mod; moderate.

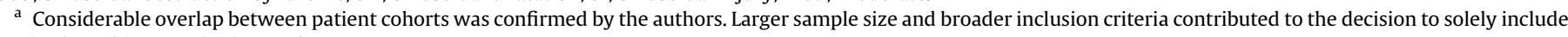
Narita (2012) in quantitative analysis.

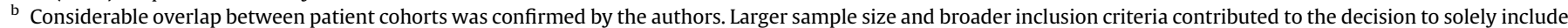
Pessaux (2010, $n=72)$ in qualitative analysis.

on postoperative mortality (Fig. 2C), with a total of 17 events. The test for overall effect showed a p-value of 0.82 with an OR of 1.21 [95\% CI 0.23-6.35]. Statistical testing for heterogeneity showed an $\mathrm{I}^{2}$ of $0 \%$ and $\mathrm{p}$-value of 0.79 . Assumption of fixed effects barely influenced the results (OR 1.15 [95\% CI 0.24-5.51], $\mathrm{p}=0.86$ ). Multiple studies described zero mortality in groups with or without SD $[15,19,22-25,43,48,52]$, or no increase in mortality rate in patients with SD [47].

As described before, Soubrane et al. presented a subgroup analysis in patients who underwent major liver resection [53]. In this study, two postoperative deaths occurred within 90 days in the SD group that consisted of 38 patients (4\%). Thirteen patients did not have SD with zero mortality.

\subsection{Secondary outcome}

\subsubsection{Liver-related morbidity}

Two studies were available for estimating the influence of SD on postoperative liver-related morbidity (Fig. 2D). The study of Gomez-Ramirez et al. included the following complications: biliary fistula, haemorrhage, abscesses, uninfected collections and liver failure [22], while Makowiec et al. included hepatic insufficiency, bilioma and/or symptomatic ascites requiring interventional or medical treatment [26]. An OR of 3.52 [95\% CI 0.31-39.91] was 


\section{A. POSTOPERATIVE OVERALL MORBIDITY}

Meta-analysis on the influence of sinusoidal dilatation (SD) grade 2-3 versus SD grade 0-1 on the morbidity rate due to any cause after partial hepatectomy for colorectal liver metastases

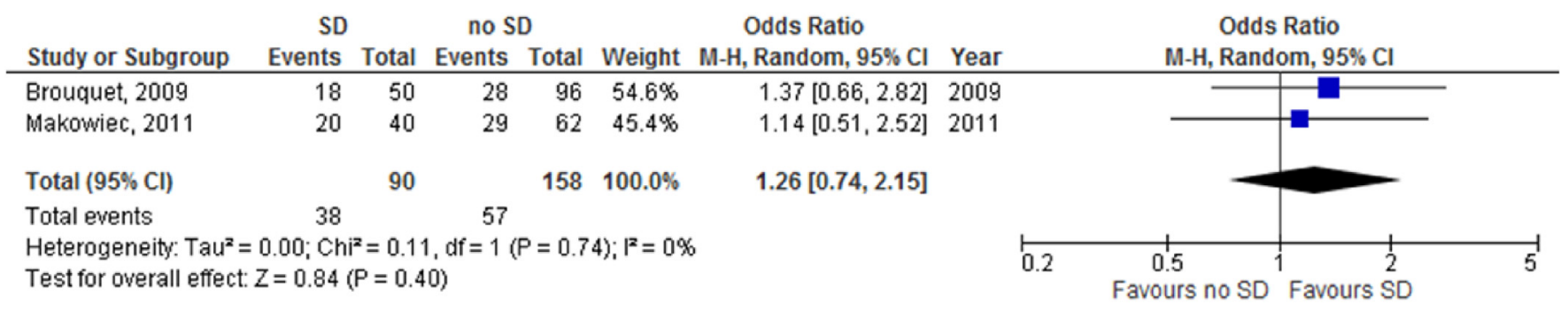

\section{B. POSTOPERATIVE LIVER FAILURE}

Meta-analysis on the influence of sinusoidal dilatation (SD) grade 2-3 versus SD grade 0-1 on the liver failure rate after partial hepatectomy for colorectal liver metastases

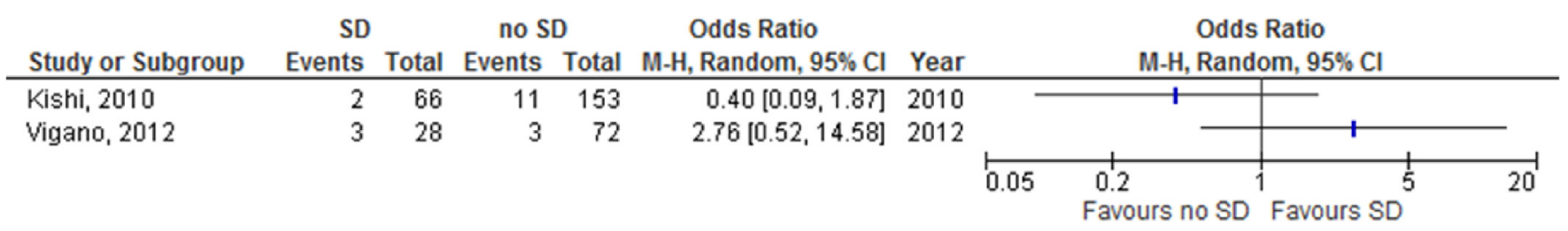

\section{POSTOPERATIVE OVERALL MORTALITY}

Meta-analysis on the influence of sinusoidal dilatation (SD) grade 2-3 versus SD grade 0-1 on the mortality rate due to any cause after partial hepatectomy for colorectal liver metastases

\begin{tabular}{|c|c|c|c|c|c|c|c|c|c|c|}
\hline \multirow[b]{2}{*}{ Study or Subgroup } & \multicolumn{2}{|c|}{ SD } & \multicolumn{2}{|c|}{ no SD } & \multicolumn{3}{|c|}{ Odds Ratio } & \multirow{2}{*}{\multicolumn{3}{|c|}{$\begin{array}{c}\text { Odds Ratio } \\
\mathrm{M}-\mathrm{H}, \text { Random, } 95 \% \mathrm{Cl}\end{array}$}} \\
\hline & Events & Total & Events & Total & Weight & $\mathrm{M}-\mathrm{H}, \mathrm{Random}, 95 \% \mathrm{Cl}$ & Year & & & \\
\hline Vauthey, 2006 & 0 & 22 & 11 & 384 & $33.6 \%$ & $0.72[0.04,12.64]$ & 2006 & & & \\
\hline Tamandl, 2011 & 0 & 21 & 4 & 175 & $31.5 \%$ & $0.89[0.05,17.03]$ & 2011 & & & \\
\hline Vigano, 2012 & 1 & 28 & 1 & 72 & $34.9 \%$ & $2.63[0.16,43.55]$ & 2012 & & & \\
\hline Total $(95 \% \mathrm{Cl})$ & & 71 & & 631 & $100.0 \%$ & $1.21[0.23,6.35]$ & & & & \\
\hline Total events & 1 & & 16 & & & & & & & \\
\hline $\begin{array}{l}\text { Heterogeneity: Tau² } \\
\text { Test for overall effec }\end{array}$ & $\begin{array}{l}0.00 ; \mathrm{Ch} \\
z=0.22\end{array}$ & $\begin{array}{l}=0.4 \\
P=0.8\end{array}$ & 2) $d f=2($ & $P=0.75$ & $9) ;\left.\right|^{2}=0 \%$ & & & 0.02 & $\begin{array}{l}0.1 \\
\text { Favours no SD }\end{array}$ & ${ }^{1}$ Favours SD \\
\hline
\end{tabular}

\section{POSTOPERATIVE LIVER-RELATED MORBIDITY}

Meta-analysis on the influence of sinusoidal dilatation (SD) grade 2-3 versus SD grade 0-1 on the liver-related morbidity rate after partial hepatectomy for colorectal liver metastases

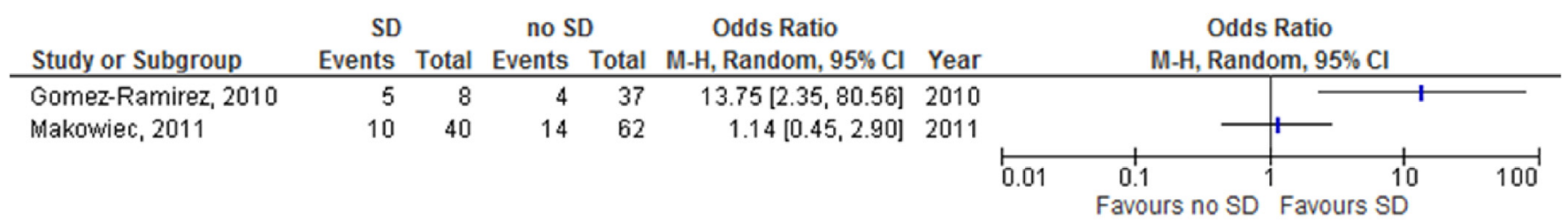

SD; sinusoidal dilatation, $\mathrm{M}-\mathrm{H}$; Mantel-Haenszel, Random; random effects model, $95 \% \mathrm{Cl}$; $95 \%$ confidence interval

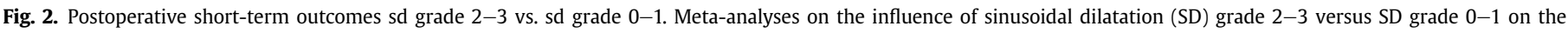

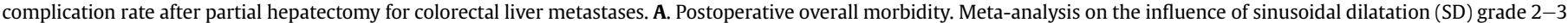

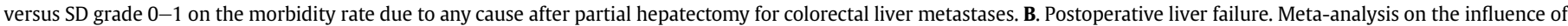

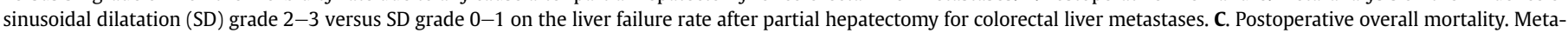

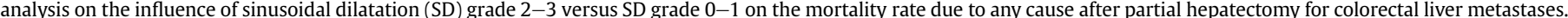

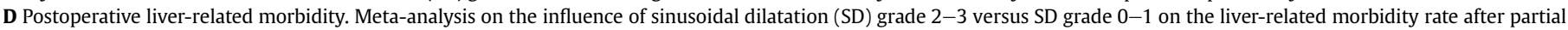
hepatectomy for colorectal liver metastases. SD; sinusoidal dilatation, M-H; Mantel-Haenszel, Random; random effects model, 95\% CI; 95\% confidence interval. 
found with a p-value of 0.31 for SD. $\mathrm{I}^{2}$ was $83 \%$ with a $\mathrm{p}$-value of $\mathrm{X}^{2}$ test of 0.01 . Overlapping of intervals between included studies was barely present; hence totals were omitted from the forest plot. In major hepatectomy only, eight out of 30 patients without SD vs. 10 out of 29 patients with SD developed liver-related complications [26].

\subsection{Sub group analysis}

Five studies compared SD grade $1-3$ with SD grade 0 . Analyses on these subgroups were performed and resulting forest plots are presented in Appendix 3. In summary, the effect of SD grade 1-3 on the primary outcome postoperative morbidity could be tested in three studies $(n=577)[20,54,57]$, liver failure in one study $(n=90)$ [20], and mortality in two studies $(n=433)[50,57]$. Again, the risk for postoperative overall morbidity after minor or major liver resection in the SD group tended to be higher (OR 1.53, 95\% CI $0.96-2.44, \mathrm{p}=0.08$ ) than in the group without SD (Appendix 3A). There was limited evidence of effect (one study) of SD on PLF, and therefore no meta-analysis was conducted on this outcome. This study showed a higher incidence of PLF, which was defined as a serum bilirubin $>50 \mu \mathrm{mol} / \mathrm{L}$ and a prothrombin time $<50 \%$ on POD 5 or thereafter, in the SD group (three out of 38 patients with SD vs. zero out of 52 patients without SD) [20]. Estimate points of effect for postoperative mortality resulted in an OR of 0.51 and p-value of 0.54 (Appendix 3B). Statistical heterogeneity analysis revealed $\mathrm{I}^{2}=0 \%$ and $\mathrm{p}$-values of 0.77 and 0.40 for postoperative overall morbidity and mortality, respectively. No mortality was observed in patient groups with and without SD in two studies [20,54]. Secondary outcome measure liver-related morbidity could be tested in two studies $[20,57]$ and yielded an OR of 2.22 (95\% CI 0.34-14.32, $\mathrm{p}=0.40)$ and $a \mathrm{I}^{2}$ of $64 \%(\mathrm{p}=0.10)$ (Appendix $\left.3 \mathrm{C}\right)$.

For major resections only, forest plots were constructed for postoperative overall morbidity and liver failure (Appendix 4). Two studies that included a total of 137 patients were available for a meta-analysis on postoperative morbidity (Appendix 4A) [20,49]. An OR of 2.00 [95\% CI 0.12-33.34] with a p-value of 0.63 for SD were found. $\mathrm{I}^{2}$ was $83 \%$ with a p-value of $\mathrm{X}^{2}$ test of 0.02 , and totals were omitted from the forest plot. The same two studies were available for a meta-analysis on postoperative liver failure (Appendix 4B). Whereas Nakano et al. defined postoperative liver failure as a serum bilirubin $>50 \mu \mathrm{mol} / \mathrm{L}$ and a prothrombin time $<50 \%$ on or after POD5 [20], Narita et al. defined this as a serum bilirubin $>50 \mu \mathrm{mol} / \mathrm{L}$ and a prothrombin time $<50 \%$ on POD5 and/or a postoperative serum bilirubin $>120 \mu \mathrm{mol} / \mathrm{L}$ [49]. An OR of 2.67 [95\% CI 0.94-7.53] with a near-significant p-value of 0.06 for SD was found. No heterogeneity was detected as reflected in an $\mathrm{I}^{2}$ of $0 \%$ with a $\mathrm{X}^{2}$ test p-value of 0.73 . No mortality in patients with or without SD was observed in two studies on major hepatectomy $[20,46]$. Liver-related morbidity was seen in the study of Nakano et al. [20], with three patients showing liver-related morbidity in the patient group with $\operatorname{SD}(n=20)$ versus one patient in the patient group without SD $(\mathrm{n}=16)$.

\subsection{Quality of the included studies}

\subsubsection{Risk of bias assessment}

Risk of bias was assessed using the modified QUIPS checklist $[40,41]$ and overall ratings are depicted in Table 1 . Thirteen articles showed an overall low risk of bias, two studies showed moderate risk of bias and ten articles were appraised as having a high risk of bias. The assessment of risk of bias per domain and sub domain for individual studies can be found in Appendix 5.

\subsubsection{GRADE assessment}

Study findings were assessed with the modified GRADE checklist [42,58] and are shown in the Summary of Findings Table (Table 2). Footnotes provide detailed information about the rationale for downgrading. In short, evidence for all outcomes was rated as very low. Each outcome was downgraded on the base of study design (phase 1 explanatory studies). Other reasons for downgrading were indirectness in definition or time period of outcome measures and imprecision in data as shown by forest plots. Only QUIPS domain 1 to 4 were taken into account for downgrading, since domains 5 and 6 assess quality of the statistical analysis which did not influence quality of the current metaanalysis because we extracted only raw data from the manuscripts. A detailed rating per domain can be found in Appendix 6. A Summary of Findings Table for outcomes on SD grade $1-3 v$ s. 0 and a detailed rating per domain can be found in Appendix 7 and 8 .

\section{Discussion}

The present study found no significant influence of moderate to severe SD (grade 2-3) in comparison to no or mild SD (grade 0-1) on outcome after partial hepatectomy. Likewise, no influence on postoperative outcome was apparent when comparing mild to severe SD (grade 1-3) to no SD (grade 0 ). After data extraction, all studies were subjected to assessment with the QUIPS and GRADE tools to grade the quality of included evidence, strength of recommendations and risk of bias. Critical evaluation subsequently showed a low to high risk of bias for individual studies and very low quality of outcome-specific evidence, thereby leading to limited confidence in the provided evidence with regards to our hypothesis. An important explanation for less trust in the provided evidence is the study design of included articles. All but one study consisted of explanatory phase 1 studies, which are performed in early phases of investigation to generate a hypothesis and are considered weaker evidence than studies which confirm the independent effect of a specific prognostic factor on outcome (phase 2 studies), or studies that explore the underlying mechanism for prognosis of certain diseases (phase 3 studies) [30,59]. Moreover, variation in inclusion criteria, sample size, wide confidence intervals crossing the null value, and different definitions of outcomes, were factors that negatively affected the quality of the evidence specified for our hypothesis. In light of these findings, no solid conclusions can be drawn and this study cannot provide clinical advice on the topic.

Some studies showed contrasting data, which may be partially explained by different inclusion criteria. While patients who received bevacizumab were intentionally excluded in some studies $[26,50]$, other studies did allow inclusion of these patients $[22,47]$. Bevacizumab, an angiogenesis inhibitor that inhibits tumour growth by binding to vascular endothelial growth factor, is often co-administered in oxaliplatin-based chemotherapy regimens for patients with CRLM [60]. Apart from the ongoing discussion about the potential benefit of prevention or reversibility of histological injury $[2,61]$, bevacizumab itself may induce relevant toxic side effects which can affect recovery after partial liver resection [62-64]. Moreover, it is usually advised to end chemotherapy, particularly when bevacizumab is co-administered, at least five weeks before liver surgery [65]. Studies included in this systematic review report a range from 2 to 9 weeks for the interval between the last cycle of chemotherapy and surgery. It is currently unclear whether pathological characteristics of SOS are reversible, if a lower grade of SOS is linked to a higher likeliness of reversibility, and in which time frame this would occur. Patients with a long time interval between chemotherapy cessation and surgery were observed to have less SD compared to a short time interval [20], whereas irreversibility of SOS and even deterioration in time have been 
Table 2

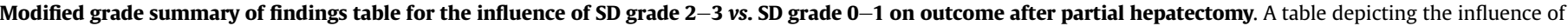

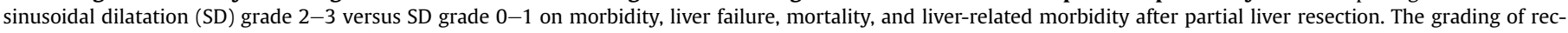

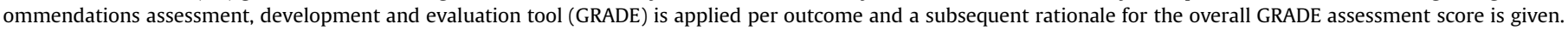

\begin{tabular}{|c|c|c|c|c|}
\hline \multicolumn{5}{|l|}{ Patient or population: Patients with CRLM } \\
\hline \multicolumn{5}{|l|}{ Setting: Hospital } \\
\hline \multicolumn{5}{|l|}{ Prognostic factor: SD grade $2-3$} \\
\hline Outcomes & Number of participants & Number of studies & Estimated effect size $(95 \% \mathrm{CI})$ & GRADE assessment $^{\mathrm{a}}$ \\
\hline $\begin{array}{l}\text { Morbidity } \\
\text { Follow-up: } 30-90 \text { days or in-hospital }\end{array}$ & 248 & 2 & OR $1.26(0.74-2.15)$ & Very low $w^{\mathrm{b}, \mathrm{c}, \mathrm{f}}$ \\
\hline $\begin{array}{l}\text { Liver failure } \\
\text { Follow-up: } 30-90 \text { days or in-hospital }\end{array}$ & 319 & 2 & Omitted due to significant heterogeneity & Very low ${ }^{\mathrm{b}, c, \mathrm{~d}, \mathrm{e}, \mathrm{f}}$ \\
\hline $\begin{array}{l}\text { Mortality } \\
\text { Follow-up: 30-90 days or in-hospital }\end{array}$ & 702 & 3 & OR $1.21(0.23-6.35)$ & Very low ${ }^{\mathrm{d}, \mathrm{f}}$ \\
\hline $\begin{array}{l}\text { Liver-related morbidity } \\
\text { Follow-up: } 30-90 \text { days or in-hospital }\end{array}$ & 147 & 2 & Omitted due to significant heterogeneity & Very low ${ }^{\mathrm{b}, \mathrm{c}, \mathrm{d}, \mathrm{e}}$ \\
\hline
\end{tabular}

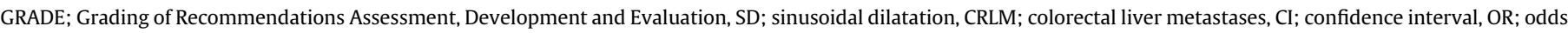
ratio.

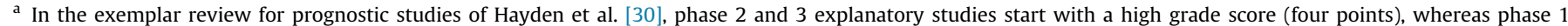

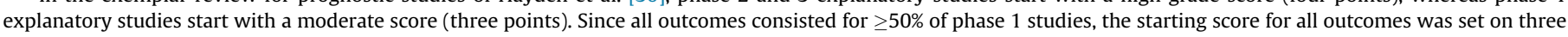
points.

b The definition of the outcome was not clearly stated in all included articles or there were differences in outcome definition between the included studies for this outcome.

c The time period for measurement of the outcome was not clearly stated in $\geq 50 \%$ of the included studies.

d (Almost) no overlap in 95\% confidence intervals and estimate points of effect could be found on both sides of the null line in meta-analysis for this outcome.

e There was significant unexplained heterogeneity for this outcome as defined by an $\mathrm{I}^{2} \geq 65 \%$ and a $\mathrm{p}$-value $<0.10$.

f This outcome contains imprecise results, defined as an inclusion of only two studies and/or an insufficient sample size, wide confidence intervals or confidence intervals crossing the null value in $\geq 50 \%$ of studies.

described by Mentha et al. [15].

Likewise, a link between the number of administered cycles of chemotherapy and grade of liver injury is uncertain, and the median number of administered cycles in this meta-analysis ranged from 6 to 12. Whereas Karoui et al. found that the morbidity rate was correlated with the number of chemotherapy cycles [46], this correlation was not confirmed by Van Der Pool et al. who compared patients who received less than six cycles with those who received six or more cycles [54]. One could speculate that patients with longer duration of chemotherapy may have had more extensive disease and therefore more complex surgical interventions. Almost all studies corrected for the extent of liver resection, but extrahepatic procedures and vascular reconstructions were not taken into account in more than half of studies. The impact of these procedures on outcome can be substantial $[66,67]$.

In patients with a critical future liver remnant due to anticipated extensive surgery, portal vein embolization (PVE) is the preferred procedure to induce preoperative enlargement of the future liver remnant [68]. The effect of SD on liver regeneration after PVE has been investigated in one study, in which PVE had a negative effect on postoperative liver regeneration [33]. Moreover, post-PVE histopathological changes in a previous report were the rationale for Vauthey et al. [55] and Brouquet et al. [44] to exclude these patients from their cohorts [69]. This resulted in a less complete reflection of the general surgical population. However, inclusion of these patients may have an impact on postoperative outcomes either by a diminished hypertrophic response or because this group of patients often undergoes extended hepatectomies and is already at higher risk.

With regard to variations in definitions, outcome after liver resection was expressed in numerous terms and time frames. Mortality was assessed within 30,60 , or 90 days after surgery or during hospital admission, and morbidity was described as overall, medical, surgical, liver-related or infectious, with no consensus on employed definitions. This underscores the necessity of a uniform outcome set after liver surgery in order to ensure clear and consistent clinically relevant data, and to allow comparison between future trials and cohort studies in meta-analyses [39].
On the basis of stated differences in inclusion criteria and outcome, which all might have influenced the outcome after liver resection to an unknown extent, ideally a phase two study in which all confounders are corrected for in a statistically appropriate way should be conducted. Our group recently initiated such a study in the form of an individual patient data meta-analysis [70].

\section{Conclusion}

This study aimed to evaluate the influence of moderate to severe SD on outcome in patients undergoing partial hepatectomy for CRLM. Although many individual studies suggest a negative impact on postoperative (liver-related) morbidity, liver failure and mortality, the present meta-analysis could not confirm this data. However, trust in the obtained evidence was low and therefore no solid conclusions can be drawn. This study emphasizes the importance of critical risk of bias assessment and evaluation of quality in meta-analyses, to provide the most robust level of evidence for clinical decision making. It also highlights the need for unambiguous definitions of outcome in surgical oncology.

\section{Conflicts of interest}

None declared.

\section{Source of funding}

No funding was received to conduct this study.

\section{Acknowledgments}

The authors would like to thank information specialist Ms. Janine Ross for performing the extensive search used in this study. Furthermore, special thanks go to Dr. Jill Hayden for her advice on application of the QUIPS and GRADE framework for prognosis studies. 
Appendix A. Supplementary data

Supplementary data related to this article can be found at http:// dx.doi.org/10.1016/j.suronc.2016.05.030.

\section{References}

[1] L. Rubbia-Brandt, V. Audard, P. Sartoretti, A.D. Roth, C. Brezault, M. Le Charpentier, B. Dousset, P. Morel, O. Soubrane, S. Chaussade, G. Mentha, B. Terris, Severe hepatic sinusoidal obstruction associated with oxaliplatin-based chemotherapy in patients with metastatic colorectal cancer, Ann. Oncol. 15 (3) (2004) 460-466.

[2] L. Rubbia-Brandt, G.Y. Lauwers, H. Wang, P.E. Majno, K. Tanabe, A.X. Zhu, C. Brezault, O. Soubrane, E.K. Abdalla, J.-N.N. Vauthey, G. Mentha, B. Terris, Sinusoidal obstruction syndrome and nodular regenerative hyperplasia are frequent oxaliplatin-associated liver lesions and partially prevented by bevacizumab in patients with hepatic colorectal metastasis, Histopathology 56 (4) (2010) 430-439.

[3] S.M. Robinson, C.H. Wilson, A.D. Burt, D.M. Manas, S.A. White, Chemotherapyassociated liver injury in patients with colorectal liver metastases: a systematic review and meta-analysis, Ann. Surg. Oncol. 19 (13) (2012) 4287-4299.

[4] V.W. Lam, C. Spiro, J.M. Laurence, E. Johnston, M.J. Hollands, H.C. Pleass, A.J. Richardson, A systematic review of clinical response and survival outcomes of downsizing systemic chemotherapy and rescue liver surgery in patients with initially unresectable colorectal liver metastases, Ann. Surg. Oncol. 19 (4) (2012) 1292-1301.

[5] Y. Seium, R. Stupp, T. Ruhstaller, P. Gervaz, G. Mentha, M. Philippe, A. Allal, C. Trembleau, J. Bauer, R. Morant, A.D. Roth, Oxaliplatin combined with irinotecan and 5-fluorouracil/leucovorin (OCFL) in metastatic colorectal cancer: a phase I-II study, Ann. Oncol. 16 (5) (2005) 762-766.

[6] R. Adam, V. Delvart, G. Pascal, A. Valeanu, D. Castaing, D. Azoulay, S. Giacchetti, B. Paule, F. Kunstlinger, O. Ghemard, F. Levi, H. Bismuth, Rescue surgery for unresectable colorectal liver metastases downstaged by chemotherapy: a model to predict long-term survival, Ann. Surg. 240 (4) (2004) 644-657 discussion 657-658.

[7] J. Agostini, S. Benoist, M. Seman, C. Julie, S. Imbeaud, F. Letourneur, N. Cagnard, P. Rougier, A. Brouquet, J. Zucman-Rossi, P. Laurent-Puig, Identification of molecular pathways involved in oxaliplatin-associated sinusoidal dilatation, J. Hepatol. 56 (4) (2012) 869-876.

[8] K. Nakamura, E. Hatano, A. Miyagawa-Hayashino, M. Okuno, Y. Koyama, M. Narita, S. Seo, K. Taura, S. Uemoto, Soluble thrombomodulin attenuates sinusoidal obstruction syndrome in rat through suppression of high mobility group box 1, Liver Int. 34 (10) (2014) 1473-1487.

[9] S.M. Robinson, J. Mann, A. Vasilaki, J. Mathers, A.D. Burt, F. Oakley, S.A. White, D.A. Mann, Pathogenesis of FOLFOX induced sinusoidal obstruction syndrome in a murine chemotherapy model, J. Hepatol. 59 (2) (2013) 318-326.

[10] X. Wang, G.C. Kanel, L.D. DeLeve, Support of sinusoidal endothelial cell glutathione prevents hepatic veno-occlusive disease in the rat, Hepatology 31 (2) (2000) 428-434.

[11] L.D. DeLeve, Y. Ito, N.W. Bethea, M.K. McCuskey, X. Wang, R.S. McCuskey, Embolization by sinusoidal lining cells obstructs the microcirculation in rat sinusoidal obstruction syndrome, Am. J. Physiol. Gastrointest. Liver Physiol. 284 (6) (2003) G1045-G1052.

[12] T. Ezzat, M.A. van den Broek, N. Davies, C.H. Dejong, A. Bast, M. Malago, D.K. Dhar, S.W. Olde Damink, The flavonoid monoHER prevents monocrotaline-induced hepatic sinusoidal injury in rats, J. Surg. Oncol. 106 (1) (2012) 72-78.

[13] C.Q. Fan, J.M. Crawford, Sinusoidal obstruction syndrome (hepatic venoocclusive disease), J. Clin. Exp. Hepatol. 4 (4) (2014) 332-346.

[14] L.D. DeLeve, R.S. McCuskey, X. Wang, L. Hu, M.K. McCuskey, R.B. Epstein, G.C. Kanel, Characterization of a reproducible rat model of hepatic venoocclusive disease, Hepatology 29 (6) (1999) 1779-1791.

[15] G. Mentha, S. Terraz, P. Morel, A. Andres, E. Giostra, A. Roth, L. Rubbia-Brandt, P. Majno, Dangerous halo after neoadjuvant chemotherapy and two-step hepatectomy for colorectal liver metastases, Br. J. Surg. 96 (1) (2009) 95-103.

[16] M.J. Overman, D.M. Maru, C. Charnsangavej, E.M. Loyer, H. Wang, P. Pathak, C. Eng, P.M. Hoff, J.N. Vauthey, R.A. Wolff, S. Kopetz, Oxaliplatin-mediated increase in spleen size as a biomarker for the development of hepatic sinusoidal injury, J. Clin. Oncol. 28 (15) (2010) 2549-2555.

[17] R. Arotcarena, V. Cales, P. Berthelemy, Y. Parent, M. Malet, F. Etcharry, S. Ferrari, A. Pariente, Severe sinusoidal lesions: a serious and overlooked complication of oxaliplatin-containing chemotherapy? Gastroenterol. Clin. Biol. 30 (11) (2006) 1313-1316.

[18] J.H. Slade, M.L. Alattar, D.R. Fogelman, M.J. Overman, A. Agarwal, D.M. Maru, R.L. Coulson, C. Charnsangavej, J.N. Vauthey, R.A. Wolff, S. Kopetz, Portal hypertension associated with oxaliplatin administration: clinical manifestations of hepatic sinusoidal injury, Clin. Colorectal Cancer 8 (4) (2009) 225-230.

[19] K. Imai, Y. Emi, K.I. Iyama, T. Beppu, Y. Ogata, Y. Kakeji, H. Samura, E. Oki, Y. Akagi, Y. Maehara, H. Baba, Kyusyu Study Group of Clinical Cancer ancillary, Splenic volume may be a useful indicator of the protective effect of bevacizumab against oxaliplatin-induced hepatic sinusoidal obstruction syndrome, Eur. J. Surg. Oncol. 40 (5) (2014) 559-566.
[20] H. Nakano, E. Oussoultzoglou, E. Rosso, S. Casnedi, M.P. Chenard-Neu, P. Dufour, P. Bachellier, D. Jaeck, Sinusoidal injury increases morbidity after major hepatectomy in patients with colorectal liver metastases receiving preoperative chemotherapy, Ann. Surg. 247 (1) (2008) 118-124.

[21] D. Tamandl, M. Klinger, S. Eipeldauer, B. Herberger, K. Kaczirek, B. Gruenberger, T. Gruenberger, Sinusoidal obstruction syndrome impairs long-term outcome of colorectal liver metastases treated with resection after neoadjuvant chemotherapy, Ann. Surg. Oncol. 18 (2) (2011) 421-430.

[22] J. Gomez-Ramirez, E. Martin-Perez, C.G. Amat, I.G. Sanz, E. Bermejo, A. Rodriguez, E. Larranaga, Influence of pre-surgical chemotherapy on liver parenchyma and post-surgical outcome of patients subjected to hepatectomy due to colorectal carcinoma metastases, Cir. Esp. 88 (6) (2010) 404-412.

[23] T. Takamoto, T. Hashimoto, K. Sano, Y. Maruyama, K. Inoue, S. Ogata, T. Takemura, N. Kokudo, M. Makuuchi, Recovery of liver function after the cessation of preoperative chemotherapy for colorectal liver metastasis, Ann. Surg. Oncol. 17 (10) (2010) 2747-2755.

[24] S. Kandutsch, M. Klinger, S. Hacker, F. Wrba, B. Gruenberger, T. Gruenberger, Patterns of hepatotoxicity after chemotherapy for colorectal cancer liver metastases, Eur. J. Surg. Oncol. 34 (11) (2008) 1231-1236.

[25] H. Komori, T. Beppu, Y. Baba, K. Horino, C. Imsung, T. Masuda, H. Hayashi, H. Okabe, R. Ootao, M. Watanabe, H. Takamori, K. Iyama, H. Baba, Histological liver injury and surgical outcome after FOLFOX followed by a hepatectomy for colorectal liver metastases in Japanese patients, Int. J. Clin. Oncol. 15 (3) (2010) 263-270.

[26] F. Makowiec, S. Mohrle, H. Neeff, O. Drognitz, G. Illerhaus, O.G. Opitz, U.T. Hopt, A. zur Hausen, Chemotherapy, liver injury, and postoperative complications in colorectal liver metastases, J. Gastrointest. Surg. 15 (1) (2011) 153-164.

[27] T.M. Pawlik, K. Olino, A.L. Gleisner, M. Torbenson, R. Schulick, M.A. Choti, Preoperative chemotherapy for colorectal liver metastases: impact on hepatic histology and postoperative outcome, J. Gastrointest. Surg. 11 (7) (2007) 860-868.

[28] A. Sahajpal, C.M. Vollmer, E. Dixon, E.K. Chan, A. Wei, M.S. Cattral, B.R. Taylor D.R. Grant, P.D. Greig, S. Gallinger, Chemotherapy for colorectal cancer prior to liver resection for colorectal cancer hepatic metastases does not adversely affect peri-operative outcomes, J. Surg. Oncol. 95 (1) (2007) 22-27.

[29] D. Takeda, H. Nitta, T. Takahara, Y. Hasegawa, N. Itou, G. Wakabayashi, Effect of preoperative chemotherapy on postoperative liver regeneration following hepatic resection as estimated by liver volume, World J. Surg. Oncol. 11 (2013) 65.

[30] J.A. Hayden, M.E. Tougas, R. Riley, R. Iles, T. Pincus, Individual recovery expectations and prognosis of outcomes in non-specific low back pain: prognostic factor exemplar review (Protocol), Cochrane Database Syst. Rev. (Issue 9) (2014).

[31] D. Moher, A. Liberati, J. Tetzlaff, D.G. Altman, P. Group, Preferred reporting items for systematic reviews and meta-analyses: the PRISMA statement, Ann. Intern. Med. 151 (4) (2009) 264-269. W64.

[32] D.F. Stroup, J.A. Berlin, S.C. Morton, I. Olkin, G.D. Williamson, D. Rennie, D. Moher, B.J. Becker, T.A. Sipe, S.B. Thacker, M. Grp, Meta-analysis of observational studies in epidemiology - a proposal for reporting, JAMA 283 (15) (2000) 2008-2012.

[33] M. Narita, E. Oussoultzoglou, M.P. Chenard, E. Rosso, S. Casnedi, P. Pessaux, P. Bachellier, D. Jaeck, Sinusoidal obstruction syndrome compromises liver regeneration in patients undergoing two-stage hepatectomy with portal vein embolization, Surg. Today 41 (1) (2011) 7-17.

[34] CADTH, Canadian Agency for Drugs and Technologies in Health, CADTH Peer Review Checklist for Search Strategies, 2013, 3pp.

[35] D. Dindo, N. Demartines, P.A. Clavien, Classification of surgical complications: a new proposal with evaluation in a cohort of 6336 patients and results of a survey, Ann. Surg. 240 (2) (2004) 205-213.

[36] S. Balzan, J. Belghiti, O. Farges, S. Ogata, A. Sauvanet, D. Delefosse, F. Durand, The "50-50 criteria" on postoperative day 5: an accurate predictor of liver failure and death after hepatectomy, Ann. Surg. 242 (6) (2005) 824-828 discussion 828-9.

[37] J.T. Mullen, D. Ribero, S.K. Reddy, M. Donadon, D. Zorzi, S. Gautam, E.K. Abdalla, S.A. Curley, L. Capussotti, B.M. Clary, J.N. Vauthey, Hepatic insufficiency and mortality in 1,059 noncirrhotic patients undergoing major hepatectomy, J. Am. Coll. Surg. 204 (5) (2007) 854-862 discussion 862-4.

[38] N.N. Rahbari, O.J. Garden, R. Padbury, M. Brooke-Smith, M. Crawford, R. Adam, M. Koch, M. Makuuchi, R.P. Dematteo, C. Christophi, S. Banting, V. Usatoff M. Nagino, G. Maddern, T.J. Hugh, J.N. Vauthey, P. Greig, M. Rees, Y. Yokoyama, S.T. Fan, Y. Nimura, J. Figueras, L. Capussotti, M.W. Buchler, J. Weitz, Posthepatectomy liver failure: a definition and grading by the international study group of liver surgery (ISGLS), Surgery 149 (5) (2011) 713-724.

[39] M.A. van den Broek, R.M. van Dam, G.J. van Breukelen, M.H. Bemelmans, E. Oussoultzoglou, P. Pessaux, C.H. Dejong, N. Freemantle, S.W. Olde Damink, Development of a composite endpoint for randomized controlled trials in liver surgery, Br. J. Surg. 98 (8) (2011) 1138-1145.

[40] J.A. Hayden, P. Cote, C. Bombardier, Evaluation of the quality of prognosis studies in systematic reviews, Ann. Intern. Med. 144 (6) (2006) 427-437.

[41] J.A. Hayden, D.A. van der Windt, J.L. Cartwright, P. Cote, C. Bombardier, Assessing bias in studies of prognostic factors, Ann. Intern. Med. 158 (4) (2013) 280-286.

[42] P. Davis, J. Hayden, J. Springer, J. Bailey, M. Molinari, P. Johnson, Prognostic factors for morbidity and mortality in elderly patients undergoing acute 
gastrointestinal surgery: a systematic review, Can. J. Surg. 57 (2) (2014) E44-E52.

[43] M.M. Aloysius, A.M. Zaitoun, I.J. Beckingham, K.R. Neal, G.P. Aithal, E.M. Bessell, D.N. Lobo, The pathological response to neoadjuvant chemotherapy with FOLFOX-4 for colorectal liver metastases: a comparative study. Virchows Arch. 451 (5) (2007) 943-948.

[44] A. Brouquet, S. Benoist, C. Julie, C. Penna, A. Beauchet, P. Rougier, B. Nordlinger, Risk factors for chemotherapy-associated liver injuries: a multivariate analysis of a group of 146 patients with colorectal metastases, Surgery 145 (4) (2009) 362-371.

[45] C. Hubert, C. Fervaille, C. Sempoux, Y. Horsmans, Y. Humblet, J.P. Machiels, F. Zech, A. Ceratti, J.F. Gigot, Prevalence and clinical relevance of pathological hepatic changes occurring after neoadjuvant chemotherapy for colorectal liver metastases, Surgery 147 (2) (2010) 185-194.

[46] M. Karoui, C. Penna, M. Amin-Hashem, E. Mitry, S. Benoist, B. Franc, P. Rougier, B. Nordlinger, Influence of preoperative chemotherapy on the risk of majo hepatectomy for colorectal liver metastases, Ann. Surg. 243 (1) (2006) 1-7.

[47] Y. Kishi, D. Zorzi, C.M. Contreras, D.M. Maru, S. Kopetz, D. Ribero, M. Motta, N. Ravarino, M. Risio, S.A. Curley, E.K. Abdalla, L. Capussotti, J.N. Vauthey, Extended preoperative chemotherapy does not improve pathologic response and increases postoperative liver insufficiency after hepatic resection for colorectal liver metastases, Ann. Surg. Oncol. 17 (11) (2010) 2870-2876.

[48] K. Miura, H. Nakano, J. Sakurai, S. Kobayashi, S. Koizumi, T. Arai, T. Shimamura R. Makizumi, K. Yamada, N. Miyajima, T. Otsubo, J. Koike, Splenomegaly in FOLFOX-naive stage IV or recurrent colorectal cancer patients due to chemotherapy-associated hepatotoxicity can be predicted by the aspartate aminotransferase to platelet ratio before chemotherapy, Int. J. Clin. Oncol. 16 (3) (2011) 257-263.

[49] M. Narita, E. Oussoultzoglou, P. Fuchshuber, P. Pessaux, M.P. Chenard, E. Rosso, C. Nobili, D. Jaeck, P. Bachellier, What is a safe future liver remnant size in patients undergoing major hepatectomy for colorectal liver metastases and treated by intensive preoperative chemotherapy? Ann. Surg. Oncol. 19 (8) (2012) 2526-2538.

[50] E. Nguyen-Khac, C. Lobry, D. Chatelain, D. Fuks, J.P. Joly, M. Brevet, B. Tramier, C. Mouly, V. Hautefeuille, B. Chauffert, J.M. Regimbeau, A reappraisal of chemotherapy-induced liver injury in colorectal liver metastases before the era of antiangiogenics, Int. J. Hepatol. 2013 (2013) 314868.

[51] P. Pessaux, E. Marzano, S. Casnedi, P. Bachellier, D. Jaeck, M.P. Chenard, Histological and immediate postoperative outcome after preoperative cetuximab: case-matched control study, World J. Surg. 34 (11) (2010) 2765-2772.

[52] P. Pessaux, F. Panaro, S. Casnedi, I. Zeca, E. Marzano, P. Bachellier, D. Jaeck, M.P. Chenard, Targeted molecular therapies (cetuximab and bevacizumab) do not induce additional hepatotoxicity: preliminary results of a case-control study, Eur. J. Surg. Oncol. 36 (6) (2010) 575-582.

[53] O. Soubrane, A. Brouquet, S. Zalinski, B. Terris, C. Brezault, V. Mallet F. Goldwasser, O. Scatton, Predicting high grade lesions of sinusoidal obstruction syndrome related to oxaliplatin-based chemotherapy for colorectal liver metastases: correlation with post-hepatectomy outcome, Ann. Surg. 251 (3) (2010) 454-460.

[54] A.E. van der Pool, H.A. Marsman, J. Verheij, F.J. Ten Kate, A.M. Eggermont J.N. Ijzermans, C. Verhoef, Effect of bevacizumab added preoperatively to oxaliplatin on liver injury and complications after resection of colorectal liver metastases, J. Surg. Oncol. 106 (7) (2012) 892-897.

[55] J.N. Vauthey, T.M. Pawlik, D. Ribero, T.T. Wu, D. Zorzi, P.M. Hoff, H.Q. Xiong, C. Eng, G.Y. Lauwers, M. Mino-Kenudson, M. Risio, A. Muratore, L. Capussotti, S.A. Curley, E.K. Abdalla, Chemotherapy regimen predicts steatohepatitis and an increase in 90-day mortality after surgery for hepatic colorectal metastases, J. Clin. Oncol. 24 (13) (2006) 2065-2072.

[56] L. Vigano, N. Ravarino, A. Ferrero, M. Motta, B. Torchio, L. Capussotti,
Prospective evaluation of accuracy of liver biopsy findings in the identification of chemotherapy-associated liver injuries, Arch. Surg. 147 (12) (2012) 1085-1091.

[57] P.S. Wolf, J.O. Park, F. Bao, P.J. Allen, R.P. DeMatteo, Y. Fong, W.R. Jarnagin, T.P. Kingham, M. Gonen, N. Kemeny, J. Shia, M.I. D'Angelica, Preoperative chemotherapy and the risk of hepatotoxicity and morbidity after liver resection for metastatic colorectal cancer: a single institution experience, J. Am. Coll. Surg. 216 (1) (2013) 41-49.

[58] A. Iorio, F.A. Spencer, M. Falavigna, C. Alba, E. Lang, B. Burnand, T. McGinn, J. Hayden, K. Williams, B. Shea, R. Wolff, T. Kujpers, P. Perel, P.O. Vandvik, P. Glasziou, H. Schunemann, G. Guyatt, Use of GRADE for assessment of evidence about prognosis: rating confidence in estimates of event rates in broad categories of patients, BMJ 350 (2015) h870.

[59] A. Huguet, J.A. Hayden, J. Stinson, P.J. McGrath, C.T. Chambers, M.E. Tougas, L. Wozney, Judging the quality of evidence in reviews of prognostic factor research: adapting the GRADE framework, Syst. Rev. 2 (2013) 71.

[60] S. Stremitzer, J. Stift, J. Singh, P. Starlinger, B. Gruenberger, D. Tamandl, T. Gruenberger, Histological response, pattern of tumor destruction and clinical outcome after neoadjuvant chemotherapy including bevacizumab or cetuximab in patients undergoing liver resection for colorectal liver metastases, Eur. J. Surg. Oncol. 41 (7) (2015) 868-874.

[61] D. Ribero, H. Wang, M. Donadon, D. Zorzi, M.B. Thomas, C. Eng, D.Z. Chang, S.A. Curley, E.K. Abdalla, L.M. Ellis, J.N. Vauthey, Bevacizumab improves pathologic response and protects against hepatic injury in patients treated with oxaliplatin-based chemotherapy for colorectal liver metastases, Cancer 110 (12) (2007) 2761-2767.

[62] P. Economopoulou, A. Kotsakis, I. Kapiris, N. Kentepozidis, Cancer therapy and cardiovascular risk: focus on bevacizumab, Cancer Manag. Res. 7 (2015) $133-143$.

[63] Z.V. Varga, P. Ferdinandy, L. Liaudet, P. Pacher, Drug-induced mitochondrial dysfunction and cardiotoxicity, Am. J. Physiol. Heart Circ. Physiol. 309 (9) (2015) H1453-H1467.

[64] B. Aussilhou, S. Dokmak, S. Faivre, V. Paradis, V. Vilgrain, J. Belghiti, Preoperative liver hypertrophy induced by portal flow occlusion before major hepatic resection for colorectal metastases can be impaired by bevacizumab, Ann. Surg. Oncol. 16 (6) (2009) 1553-1559.

[65] B. Gruenberger, D. Tamandl, J. Schueller, W. Scheithauer, C. Zielinski, F. Herbst, T. Gruenberger, Bevacizumab, capecitabine, and oxaliplatin as neoadjuvant therapy for patients with potentially curable metastatic colorectal cancer, J. Clin. Oncol. 26 (11) (2008) 1830-1835.

[66] C.H. Dejong, Vascular reconstruction combined with liver resection for malignant tumours, Br. J. Surg. 100 (13) (2013) 1776.

[67] S.K. Reddy, T.M. Pawlik, D. Zorzi, A.L. Gleisner, D. Ribero, L. Assumpcao, A.S. Barbas, E.K. Abdalla, M.A. Choti, J.N. Vauthey, K.A. Ludwig, C.R. Mantyh, M.A. Morse, B.M. Clary, Simultaneous resections of colorectal cancer and synchronous liver metastases: a multi-institutional analysis, Ann. Surg. Oncol. 14 (12) (2007) 3481-3491.

[68] K.P. van Lienden, J.W. van den Esschert, W. de Graaf, S. Bipat, J.S. Lameris, T.M. van Gulik, O.M. van Delden, Portal vein embolization before liver resection: a systematic review, Cardiovasc. Interv. Radiol. 36 (1) (2013) 25-34.

[69] J.N. Vauthey, A. Chaoui, K.A. Do, M.M. Bilimoria, M.J. Fenstermacher C. Charnsangavej, M. Hicks, G. Alsfasser, G. Lauwers, I.F. Hawkins, J. Caridi, Standardized measurement of the future liver remnant prior to extended liver resection: methodology and clinical associations, Surgery 127 (5) (2000) $512-519$.

[70] R.D. Riley, P.C. Lambert, G. Abo-Zaid, Meta-analysis of individual participant data: rationale, conduct, and reporting, BMJ 340 (2010) c221. 